\title{
Desalination of Seawater via Progressive Freeze Concentration with Anti-supercooling Rotating Crystallizer
}

\author{
Mazura Jusoh, Farah Hanim Ab. Hamid, Norshafika Yahya, and Zaki Yamani Zakaria
}

\begin{abstract}
In this work, a rotating crystallizer with antisupercooling holes was introduced as a new technology for water purification of seawater through progressive freeze concentration, where pure water is produced in the form of ice crystal block, which leaves behind a higher concentration solution. This paper presents the investigations of the effect of initial concentration and rotation time and the efficiency of the system was reviewed based on the effective partition constant $(K)$, desalination rate $\left(R_{d}\right)$ and efficiency of concentration $(\mathbf{E} \%)$. The system has achieved its best performance at low initial concentration which is $25 \mathrm{~g} / \mathrm{L}$ and rotation time of four hours.
\end{abstract}

Keywords-freeze concentration, water purification, ice crystal, desalination

\section{Introduction}

The world is currently facing a severe shortage of clean water supply in certain parts of the globe. On the other hand, the amount of water usage is increasing at an alarming rate. The latest trend of human population growth which is increasing extremely has caused the existing water resources to fail in meeting the water supply demand [1]. In addition, the triggered growth of industrialization, tourism, and agriculture development also contributes to the high demand of water supply [2, 3]. Researchers have been working hard to discover the best solution to address this problem. The total global desalination capacity is around 66.4 million $\mathrm{m}^{3}$ per day and it is expected to reach about 100 million $\mathrm{m}^{3}$ per day by 2015 [3]. This increment shows the importance of desalination method in producing freshwater [4].

The desalination process takes a huge amount of pressure or heat to separate the water from the salt and other impurities, which requires energy and therefore money [5]. The search for improved desalination method led to the use of freeze concentration method [5]. In freeze concentration, the solution is physically separated by making pure ice in solution. It involves fractional crystallization of water and subsequent removal of the ice. The principle of freezeconcentration is based on the solidification phenomena of water.

Mazura Jusoh, Farah Hanim Ab. Hamid, Norshafika Yahya, and Zaki Yamani Zakaria

Faculty of Chemical and Energy Engineering,

Universiti Teknologi Malaysia

81310 UTM Skudai, Johor, Malaysia
During ice crystal formation, solutes are rejected by the nature of ice crystal lattice which is formed by pure water. Water solidification process forming the small dimension ice crystal lattice makes the inclusion of any impurities impossible except for fluorohydric acid and ammonia, thus there is no solute contaminants in ice [6]. Progressive freeze concentration (PFC) process has been found to be one of the methods to form a single large ice crystal. The ice crystal is formed on the surface of the conducting material where the cooling is supplied. Impurities are separated from the ice phase during the ice crystals formation.

Energy consumption is one of the main advantages of freeze desalination process [7], where only $420 \mathrm{~kJ}$ of energy is required to remove salt and produce $1 \mathrm{~kg}$ of fresh water. This energy is six times lower than the energy required by MSF [8]. However, ice handling after the process is regarded as one of the complications in dealing with this system [9]. Design with a good productivity and efficiency would be a favour in the application of PFC system. In order to amend the weaknesses of previous conventional designs, several new designs for PFC system have been developed especially on solution movement such as stirring [10, 11], ultrasonic radiation [12, 13], bubble-flow [14, 15], agitation and aeration [16] and also by oscillatory motion [6, 17]. In this study, rotation of crystalliser was introduced as an agent of target solution movement, equipped with antisupercooling holes to eliminate ice seeding stage.

In PFC, there are several factors that could affect the efficiency of the system and the thawed ice quality [18] including solution flow rate, initial concentration, coolant temperature and operating time. However, this present article is focusing on the effect of initial concentration and rotation time due to the fact that these parameters are the two that are the most significant in influencing the system performance and economical aspect.

\section{Material and Methods}

\section{A. Feed Samples}

A saline solution was used throughout the experiments as raw material. In order to make saline solution, sodium chloride was well-mixed with pure water. A $50 \%$ (v/v) ethylene glycol solution was used as coolant in the water bath. Ethylene glycol is commonly applied to transfer heat in very low temperature processes.

\section{B. Laboratory Equipment}

The laboratory equipment for PFC is composed of three parts including a cooling bath, a motor, and the newly designed rotating crystallizer. Fig. 1 illustrates the schematic 
view of the experimental setup for PFC system used in this research. The rotating crystallizer with anti-supercooling holes was invented to ensure that the initial supercooling can be prevented. This features of holes provide room for nucleation and crystallization of pure water molecules to take place, where the water molecules are cooled down to below freezing point earlier than the average bulk solution molecules, since it is nearly in contact with the wall which is cooled by the coolant. In addition to the aforementioned statement, there will be higher chance of ice nucleation with lower opportunity for the contaminant to be trapped in the ice due to the higher freezing point of the pure water molecules compared to the solution that contains foreign solute molecule [10]. In addition, the ice developed in these holes generates more ice crystal with high purity. The advantage of this feature is that the ice lining process can be neglected which makes the operation easier. As explained, it can be clarified that this process applies the same theory as seeding process. Therefore, the time consumption can be reduced.

This crystallizer is attached to a motor to rotate the crystallizer in order to induce solution movement. A set of baffle is also attached to the crystallizer wall which acts as a stirrer, to reduce the accumulation of solute near the ice front. This baffle is detachable, so that it makes the sampling and cleaning process much easier. A thermocouple was located in the middle of the solution in the crystallizer to measure the temperature changes during crystallization process. This thermocouple is attached with Picolog recorder, and all data are displayed on the computer. At the end of experiment, a salinometer was used to measure the concentration of ice and also the concentrated solution.

\section{Experimental Procedure}

A saline solution was first kept in the freezer at $2^{\circ} \mathrm{C}$ to $3^{\circ} \mathrm{C}$ as the initial temperature of the sample should be near the water freezing temperature. Cubes of saline solution were mixed with the sample to maintain the temperature during the feeding process. The saline solution was fed directly into the crystallizer. In order to allow the crystallization process to occur, the crystallizer then was immersed into the cooling bath at the desired temperature and rotation speed. After the designated time, the rotation was stopped and the crystallizer was taken out to be thawed. The concentrated solution was drained out completely and a sample of the ice

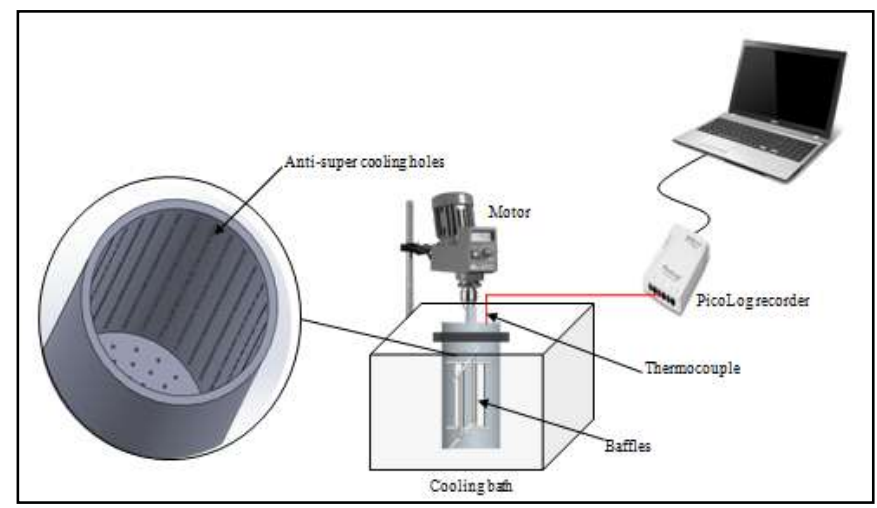

Figure 1. Experimental Setup layer produced was collected. The salinity of each sample was then measured using a salinometer.

\section{Evaluation Methods}

\section{A. Effective Partition Constant}

The exclusion of solute molecules from the moving ice front and the interface between the ice and solution phases is the main mechanism of concentration in PFC [19]. For evaluation method, effective partition constant (K) was reviewed to determine the system performance. The $\mathrm{K}$ value is related to the quality of the ice produced which can be determined by the following equation [19]:

$$
\mathrm{K}=\mathrm{C}_{\mathrm{S}} / \mathrm{C}_{\mathrm{L}}
$$

where, $C_{S}$ is concentration of ice and $C_{L}$ is concentration of the concentrate. In this case, the concentration is represented by salinity. Based on the equation of solute mass balance [19], the equation of effective partition constant, K can be integrated as follows:

$$
(1-\mathrm{K}) \log \left(\mathrm{V}_{\mathrm{L}} / \mathrm{V}_{\mathrm{o}}\right)=\log \left(\mathrm{C}_{\mathrm{o}} / \mathrm{C}\right)
$$

where $\mathrm{V}_{\mathrm{L}}$ is defined as the concentrate volume, is the initial volume of solution, $\mathrm{C}_{\mathrm{o}}$ is the initial concentration of the solution and $\mathrm{C}_{\mathrm{L}}$ is the concentration of concentrate. Equation (2) was applied for evaluation method in this research. In any condition, lower $\mathrm{K}$ value shows higher efficiency of the system. According to Fujioka et al. (2013) [2], the effect of desalination increases when the $\mathrm{K}$ value is smaller. Apart from that, the purity of ice produced can be determined based on its measured salinity. Lower salinity means higher salinity reduction of ice produced. Thus, the lowest K-value and lowest salinity of ice are considered as the favourable conditions for the system.

\section{B. Efficiency of Concentration}

The concentration increment in solution relative to the quantity of $\mathrm{NaCl}$ remaining in the ice fraction is defined as efficiency (E \%) [20-22]. In theory, the lower the $\mathrm{NaCl}$ content remaining in the ice fraction, the more concentrated the solution will be. The efficiency can be calculated using Eq. (3) as follows:

$$
\text { Efficiency }(\%)=\frac{C_{L}-C_{i}}{C_{L}} \times 100
$$

where $\mathrm{C}_{\mathrm{L}}$ and $\mathrm{C}_{\mathrm{i}}$ are the concentration of $\mathrm{NaCl}$ in the concentrated solution and ice fraction, respectively.

\section{Desalination Rate}

In order to ascertain the performance of desalination process, desalination rate, $\mathrm{R}_{\mathrm{d}}$ was employed into calculation using Eq. (4) as follows [18]:

$$
\mathrm{R}_{\mathrm{d}}=\left(\mathrm{C}_{0}-\mathrm{Ci}\right) / \mathrm{C}_{0} \times 100 \%
$$


where $\mathrm{C}_{\mathrm{o}}$ and $\mathrm{C}_{\mathrm{i}}$ are the initial concentration of the solution and the concentration of ice produced respectively. The desalination rate also can be an indicator to discover the efficiency of the system. The higher value of $R_{d}$ indicates a better performance for the system.

\section{Result and Discussions}

\section{A. Effect of Initial Concentration}

This study was carried out to determine the effect of initial concentration on the efficiency of the PFC system. The initial solution salinity was chosen based on the average seawater salinity which is 25 to $45 \mathrm{~g} / \mathrm{L}$. As the initial salinity was varied, other parameters were kept constant with rotation time, coolant temperature and rotation speed of four hours, $-8^{\circ} \mathrm{C}$ and $300 \mathrm{rpm}$, respectively.

Previous studies have stated that although the operating conditions were much varied, the results seem to show that $\mathrm{K}$ is dependent on the initial solute concentration. It can be shown that higher initial concentration resulted in higher $\mathrm{K}$, which means lower efficiency for the system and vice versa. Theoretically, lower value of initial concentration will give lower value of K. From the graph in Fig. 2, it can be observed that at the lowest initial concentration, the value of $\mathrm{K}$ is also the lowest as compared to the rest. This is in line with the theories from previous studies for the following initial concentration where $K$ value increases as the concentration increases. This means that the $\mathrm{K}$ value depends on the initial amount of solute in the solution to be concentrated. At lower initial concentration, only a small amount of salt is contained in the solution, resulting lower accumulation of solutes at an ice liquid interface in order to produce more concentrate [23]. As a result, lower initial concentration has lower $\mathrm{K}$, which means high efficiency.

\section{B. Effect of Rotation Time}

For this part, the determination of the effect of rotation time towards $\mathrm{K}$ value, $\mathrm{R}_{\mathrm{d}}$ and $\mathrm{E} \%$ has been done. Time is an important parameter that needs to be investigated for this system. The rotation time was varied at five different points and the other parameters were kept constant with rotation speed at 300rpm, coolant temperature of $-8^{\circ} \mathrm{C}$ and $35 \mathrm{~g} / \mathrm{L}$ of initial solution concentration.

The effect of rotation time towards $\mathrm{K}$ value, $\mathrm{R}_{\mathrm{d}}$ and $\mathrm{E} \%$ is shown in Fig. 3. Basically, rotation time might be giving different values of $\mathrm{K}$ each time. This is because rotation time is defined as the time provided for crystallization to occur, in which the feed solution is concentrated and the pure water will be crystallized. From the plotted graph, it is observed that the value of $\mathrm{K}$ reduced with rotation time until it reaches its minimum point. The graph shows that a suitable crystallization time of four hours is the best condition for the PFC process where the $\mathrm{K}$-value is the lowest with 0.376 . Consequently, as the rotation time progressed further than four hours, higher $\mathrm{K}$ can be seen, which is undesirable for this system.

Apparently, at this point of rotation time, the ice formed has nearly filled the crystallizer completely, resulting in just a narrow path for the concentrate to pass

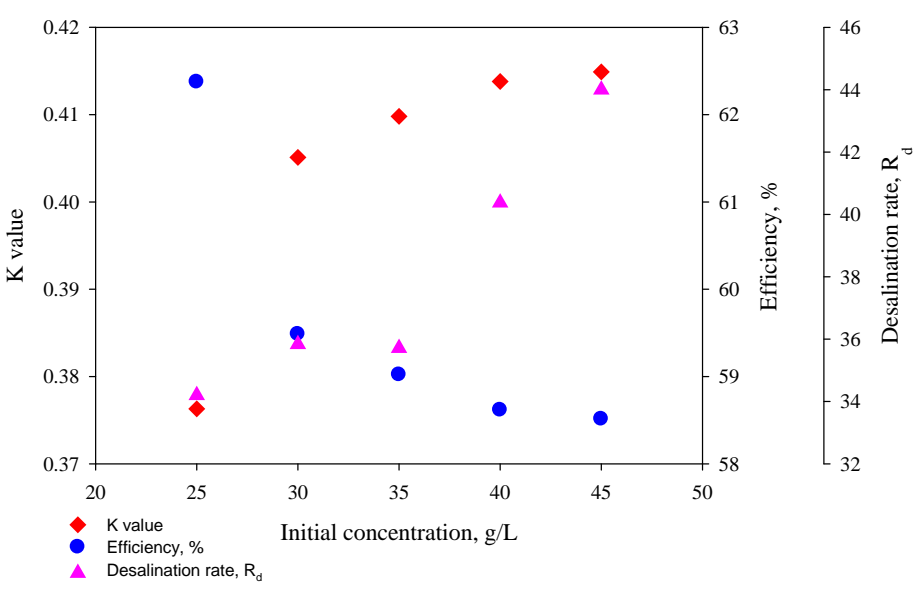

Figure 2. Effect of initial concentration on $K$ value, $R_{d}$ and $E \%$

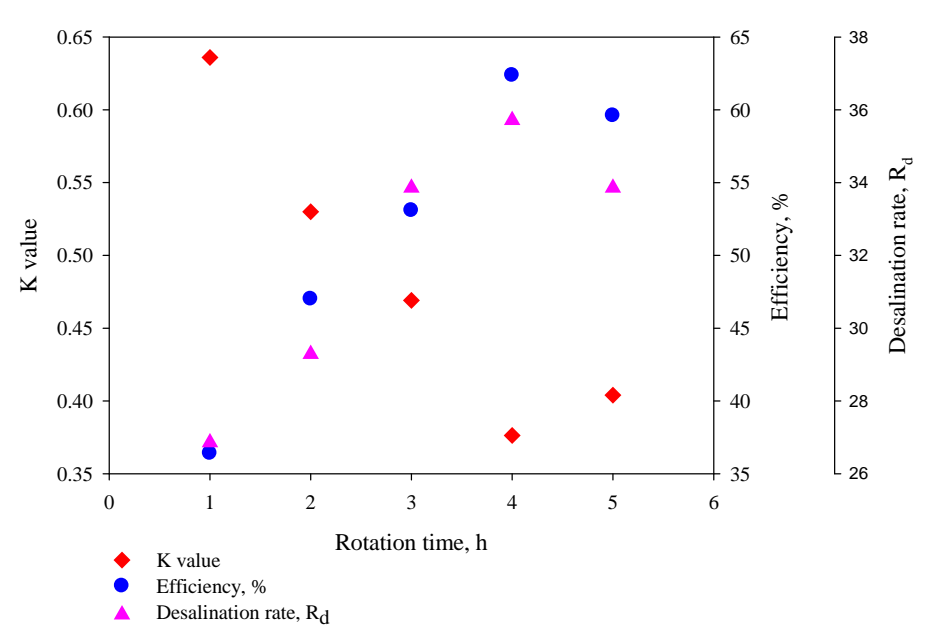

Figure 3. Effect of rotation time toward $\mathrm{K}$ value, $\mathrm{R}_{\mathrm{d}}$ and $\mathrm{E}$

through thus leaving the contaminants to be trapped in the ice crystal formed on the wall. Obviously, the longer rotation time applied will reduce the diameter of the liquid phase path. As a consequence, the chance for contamination of ice formed is higher due to the saturation of solute in the solution.

\section{Acknowledgment}

The financial supports of Research University Grant (04H46) and Fundamental Research Grant Scheme (4F224) from Universiti Teknologi Malaysia and Ministry of Education (MOE) are gratefully acknowledged.

\section{References}

[1] P.G. Youssef, R.K. Al-Dadah and S.M. Mahmoud, Comparative analysis of desalination technologies, Energy Procedia. 2014, vol. 61, pp. 2604-2607.

[2] R. Fujioka, L.P. Wang, G. Dodbiba and T. Fujita, Application of progressive freeze-concentration for desalination, Desalination. 2013, vol. 319, pp. 33-37.

[3] N. Ghaffour, T.M. Missimer and G.L. Amy, Technical review and evaluation of the economics of water desalination: Current and future challenges for better water supply sustainability, Desalination 2013, vol. 309 , pp. 197-207. 
[4] A.A. Al-Hajouri, A.S. Al-Amoudi and A.M. Farooque, Long term experience in the operation of nanofiltration pretreatment unit for seawater desalination at swcc swro plant, Desalination and Water Treatment. 2012, vol. 51, pp. 1861-1873.

[5] P.M. Williams, M. Ahmad, B.S. Connolly and D.L. Oatley-Radcliffe, Technology for freeze concentration in the desalination industry, Desalination. 2015, vol. 356, pp. 314-327.

[6] O. Lorain, P. Thiebaud, E. Badorc and Y. Aurelle, Potential of freezing in wastewater treatment: Soluble pollutant applications, Water Res. 2001,vol. 35, pp.541-547.

[7] P.M. Williams, M. Ahmad and B.S. Connolly, Freeze desalination: An assessment of an ice maker machine for desalting brines, Desalination. 2013, vol. 308, pp. 219-224.

[8] A.A.A. Attia, New proposed system for freeze water desalination using auto reversed r-22 vapor compression heat pump, Desalination. 2010, vol. 254, pp. 179-184.

[9] M.V. Rane and Y.S. Padiya, Heat pump operated freeze concentration system with tubular heat exchanger for seawater desalination, Energy Sustain. Dev. 2011, vol. 15, pp. 184-191.

[10] L. Liu, T. Fuji, K. Hayakawa and O. Miyawaki, Prevention of initial supercooling in progressive freeze concentration, Biosci. Biotechnol. Biochem. 1998, vol. 62, pp. 2467-2469.

[11] G. Gay, O. Lorain, A. Azouni and Y. Aurelle, Wastewater treatment by radial freezing with stirring effects, Water Res. 2003, vol. 37, pp. 25202524.

[12] K. Kawasaki, A. Matsuda and H. Kadota, Freeze concentration of equal molarity solutions with ultrasonic irradiation under constant freezing rate: Effect of solute, Chem. Eng. Res. Des. 2006, vol. 84:, pp. 107-112.

[13] A. Matsuda, K. Kawasaki and H. Kadota, Freeze concentration with supersonic radiation under constant freezing rate effect of kind and concentration of solutes, J. Chem. Eng. Jpn. 1999, vol. 32, pp. 569-572.

[14] Y. Shirai, M. Wakisaka, O. Miyawaki and S. Sakashita, Effect of seed ice on formation of tube ice with high purity for a freeze wastewater treatment system with a bubble-flow circulator, Water Res. 1999, vol. 33, pp. 1325-1329.

[15] A. Rich, Y. Mandri, D. Mangin, A. Rivoire, S. Abderafi, C. Bebon, N. Semlali, J.-P. Klein, T. Bounahmidi, A. Bouhaouss and S. Veesler, Sea water desalination by dynamic layer melt crystallization: Parametric study of the freezing and sweating steps, J. Cryst. Growth. 2012, vol. 342, pp. 110-116.

[16] M. Wakisaka, Y. Shirai and S. Sakashita, Ice crystallization in a pilotscale freeze wastewater treatment system, Chem. Eng. Process. 2001, vol. 40, pp. 201-208.

[17] E. Iritani, N. Katagiri, K. Okada, D.-Q. Cao and K. Kawasaki, Improvement of concentration performance in shaking type of freeze concentration, Sep. Purif. Technol. 2013, vol. 120, pp. 445-451.

[18] C.S. Luo, W.W. Chen and W.F. Han, Experimental study on factors affecting the quality of ice crystal during the freezing concentration for the brackish water, Desalination. 2010,vol. 260, pp. 231-238.

[19] L. Liu, O. Miyawaki and K. Nakamura, Progressive freeze concentration of model liquid food, Food Sci. Technol. Int. Tokyo. 1997, vol. 3, pp. 348-352.

[20] G. Petzold, K. Niranjan and J.M. Aguilera, Vacuum-assisted freeze concentration of sucrose solutions, J. Food Eng. 2013, vol. 115, pp. 357361.

[21] E. Hernández, M. Raventós, J.M. Auleda and A. Ibarz, Freeze concentration of must in a pilot plant falling film cryoconcentrator, Innovative Food Sci. Emerg. Technol. 2010, vol. 11, pp. 130-136.

[22] J. Sánchez, Y. Ruiz, M. Raventós, J.M. Auleda and E. Hernández, Progressive freeze concentration of orange juice in a pilot plant falling film, Innovative Food Science \& Emerging Technologies. 2010, vol. 11, pp. 644651.

[23] O. Miyawaki, L. Liu, Y. Shirai, S. Sakashita and K. Kagitani, Tubular ice system for scale-up of progressive freeze-concentration, J. Food Eng. 2005, vol. 69, pp. 107-113.

[24] M. Aider and D. de-Halleux, Passive and microwave-assisted thawing in maple sap cryoconcentration technology, J. Food Eng. 2008,vol. 85, pp. $65-72$.
[25] P. Prawitwong, S. Takigami and G.-O. Phillips, Phase transition behavior of sorbed water in konjac mannan., Food Hydrocolloids 2007, vol. 21, pp. 1368-1373.

About Author (s):

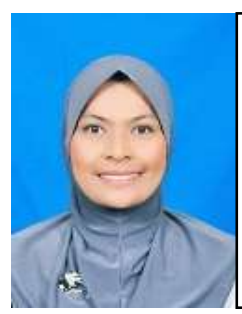

She is a Senior Lecturer in Faculty of Chemical Engineering at Universiti Teknologi Malaysia, Malaysia and specialising in separation processes especially in crystallisation technology. 